\title{
MộT Số YẾU TỐ ẢNH HƯởNG TớI NỒNG Độ HbA1c Ở BÊ̂NH NHÂN ĐÁI THÁO ĐƯỜNG TÍP 2
}

\author{
Châu Thiên Bình*, Ngô Phi Nhựt Thi*, Châu Hữu Hầu*
}

\section{TÓM TẮT}

Mục tiêu: Xác định một số yếu tố ảnh hưởng đến nồng độ $\mathrm{HbA1c}$ trển người bệnh đái tháo đường (ĐTĐ) típ 2. Phương pháp: Mô tả cắt ngang có phân tích. Nghiên cứu trên bệnh nhân ngoại trú tại Bệnh viện đa khoa Nhật Tân, An Giang, từ tháng 5/2021 đển tháng 7/2021. Kết quả: Trên tổng số bểnh nhân đái tháo đường típ 2 là 340, chúng tôi thu được 20 chỉ số có liên quan tới nhân khẩu học, thời gian mắc bệnh, thói quen sinh hoạt, hoạt động thể lực, hiểu biết vể bệnh, các chỉ số cận lâm sàng... Sau khi phân tích thống kê so sánh nồng độ HbA1c và các biến độc lập, có 6 chỉ số làm tăng nồng độ HbA1c khác biệt có ý nghĩa thống kê: hoạt động thể lực kém so với tốt $(9,22 \pm 1,77$ và $7,74 \pm 1,38)$; số năm mắc bệnh $\geq 6$ năm so với $<6$ năm $(9,27 \pm 1,73$ và $7,96 \pm 1,53)$; nữ so với nam $(8,89 \pm 1,84$ và $7,94 \pm 1,30)$; không tuân thủ và tuân thủ dùng thuốc $(9,14 \pm 1,81$ và $8,33 \pm$ $1,69)$; tăng vả không tăng huyết áp $(8,84 \pm 1,96$ so với $8,42 \pm 1,60)$; thiếu và có kiến thức về ĐTĐ $(8,56$ $\pm 1,73$ so với 8,65 $\pm 1,83)$. Kết luận: Các yếu tố liên quan đến giảm nồng độ $\mathrm{HbA} 1 \mathrm{c}$ trong nghiên cứu này bao gồm có hoạt động thể lực tốt, ĐTĐ dưới <6 năm, giới tính nam, tuân thủ dừng thuốc tốt, kiểm soát huyết áp tốt, có kiến thức tốt về bệnh. Trên cơ sở nghiên cứu này, chúng tôi khuyến cáo để ngừa và giảm bệnh ĐTĐ típ 2 cần tăng cường hoạt động thể lực, tăng cường giáo dục kiến thức vể phòng và điều trị bệnh đái tháo đường típ 2, kiểm soát huyết áp tốt và cần tuân thủ dùng thuốc.

Tư khóa: Đái tháo đường (ĐTÐ) típ 2, HbA1c.

\section{SUMMARY}

\section{SOME FACTORS AFFECTING HBA1C LEVEL}

IN TYPE 2 DIABETES PATIENTS (T2DM)

Objectives: To determine some factors affecting HbA1c concentration in patients with T2DM. Methods: Descriptive cross-sectional analysis. Study on outpatients at Nhat Tan General Hospital, An Giang, from May 2021 to July 2021. Results: Out of a total of 340 patients with T2DM, we obtained 20 indicators related to demographics, duration of disease, lifestyle habits, physical activity, and knowledge of the disease, paraclinical indicators... After statistical analysis comparing HbA1c level and independent variables, there were 6 factors that increased HbA1c levels with statistically significant differences with $p<0,05$ : poor versus good physical activity $(9.22 \pm 1.77$ vs $7.74 \pm 1.38)$; the number of

\section{*Bênhh viện Nhật Tân}

Chịu trách nhiệm chính: Châu Thiên Bình

Email: chauthienbinh@gmail.com

Ngày nhận bài: 11.8 .2021

Ngày phản biên khoa họ: 5.10 .2021

Ngày duyệt bài: 15.10.2021 years with $T 2 D M \geq 6$ years versus $<6$ years $(9.27 \pm$ 1.73 vs $7.96 \pm 1.53)$; female versus male $(8.89 \pm 1.84$ vs $7.94 \pm 1.30)$; non-compliance and compliance to medication ( $9.14 \pm 1.81$ vs $8.33 \pm 1.69)$; hypertension versus normotension ( $8.84 \pm 1.96$ vs $8.42 \pm 1.60)$; lack of knowledge versus knowledge about T2DM $(8.65 \pm 1.83$ vs $8.56 \pm 1.73)$. Conclusion: The factors related to the reduction of HbA1c levels in this study included good physical activity, having T2DM for less than 6 years, male gender, good knowledge of the disease, good adherence to medication and good blood pressure control. On the basis of this study, we recommend that in order to prevent and reduce T2DM, it is necessary to increase physical activity, increase knowledge about prevention and treatment of T2DM, control blood pressure well, and drug compliance.

Keywords: Type 2 diabetes (T2DM), HbA1c.

\section{I. ĐẶT VẤN ĐỀ}

Bệnh đái tháo đường (ĐTĐ) típ 2 được xác định bởi tăng đường huyết và kháng insulin đồng thời có suy giảm tương đối trong bài tiết insulin. Sự hiện diện của kháng insulin giải thích mối liên hể lâm sàng chặt chẽ của bệnh ĐTĐ típ 2 với béo phì và các trạng thái kháng insulin khác. Đây là một tình trạng nghiêm trọng, lâu dài, có ảnh hưởng lớn đển chất lượng cuộc sống của cá nhân, gia đình và xã hội trên toàn thế giới. ĐTĐ nằm trong số 10 nguyên nhân gây tử vong hàng đầu ở người lớn. Có ba loại ĐTĐ: Típ 1, típ 2 và ĐTÐ thai kỳ. Trong đó ĐTĐ típ 2 chiếm 90\% các trường hợp ĐTÐ [1].

Liên đoàn ĐTĐ Quốc tế (IDF) đã báo cáo tỷ lệ mắc bệnh ĐTĐ toàn câuu năm 2019 ước tính 9,3\% dân số (463 triệu người), sẽ tăng lên $10,2 \%$ (578 triệu người) vào năm 2030 và 10,9\% (700 triệu người) vào năm 2045. Tỷ lệ mắc ở thành thị cao hơn khu vực nông thôn $(10,8 \%$ so với $7,2 \%)$ và ở nước có thu nhập cao có tỷ lệ mắc cao hơn nước có thu nhập thấp $(10,4 \%$ so với $4,0 \%)$. Khoảng một nửa số người đang sống với bệnh ĐTĐ (độ tuổi 20-79) vẫn chưa được chẩn đoán $(46,5 \%)$. Hiện có khoảng dưới nửa tỷ người mắc ĐTĐ trên toàn thế giới, dự kiến sẽ tăng $25 \%$ vào năm 2030 và $51 \%$ vào nằm 2045 [1].

Ở Việt Nam, bênh ĐTĐ típ 2 cũng tăng nhanh như các nước trên thế giới: vào năm 1990 của thế kỷ trước, tỷ lệ bệnh ĐTĐ chỉ là 1,1\% (ở Hà Nội), 2,52\% (ở TP. Hồ Chí Minh), 0,96\% (ở TP. Huế). Đến năm 2012, Bệnh viện Nội tiết Trung ương cho biết tỷ lệ hiện mắc ĐTĐ trển toàn quốc 
ở người trưởng thành là 5,42\%, tỷ lệ ĐTĐ chưa được chẩn đoán trong cộng đồng là 63,6\% [2].

Để giảm tỷ lệ ĐTĐ típ 2 trong cộng đồng phải bao gồm nhiều hành động như giảm béo phì, ăn uống điều độ, năng vận động, hiểu biết về bệnh lý, tuân thủ điều trị,...Để đánh giá các vấn đề nêu trên, chúng tôi đề ra nghiên cứu về các yếu tố ảnh hưởng đến nồng độ HbA1c. Qua đó đề ra các biện pháp phòng và điều trị bệnh ĐTĐ típ 2 .

\section{II. ĐỐI TƯợNG VÀ PHƯƠNG PHÁP NGHIÊN CỨU}

2.1 Đối tượng nghiên cứu: Nghiên cứu được thực hiện trên 340 bệnh nhân ĐTĐ khám và điều trị ngoại trú tại Bệnh viện đa khoa Nhật Tân, An Giang.

Tiêu chí lựa chọn: Những người được chẩn đoán là ĐTÐ típ 2 đang điều trị ngoại trú tại khoa khám bệnh của Bệnh viện năm 2021, có thời gian mắc bệnh ít nhất 6 tháng, có khả năng tham gia phỏng vấn và đồng ý tham gia nghiên cứu.

Tiêu chuẩn loại trừ: Người bệnh được xác định tiền ĐTÐ, ĐTĐ thai kỳ, ĐTÐ típ 1; người bệnh không đồng ý tham gia nghiên cứu và người bệnh bỏ trị trong thời gian nghiên cứu.

\subsection{Phương pháp nghiên cứu:}

Thiết kế nghiên cứu: Mô tả cắt ngang kết hợp phân tích để xác định yếu tố ảnh hưởng.

Cỡ mẫu: được tính theo công thức ước lượng một tỷ lệ $\mathrm{n}=\mathrm{Z}^{2}{ }_{1-\mathrm{a} / 2} \frac{p(1-p)}{d^{2}}$

Dựa trên nghiên cứu cắt ngang và tiến cứu vào năm 2012 của chương trình Đánh giá ĐTÐ Liên Châu Á (JADE- Joint Asia Diabetes Evaluation Program) tại Việt Nam với cõ mẫu 705 bệnh nhân ĐTÐ típ 2 điều trị ngoại trú, tỷ lệ đạt mục tiêu $\mathrm{HbA1c}<7 \%$ là $30 \%$ [9]. Trong nghiên cứu này, chúng tôi chọn $\mathrm{p}$ là tỳ lệ bệnh nhân đạt được HbA1c mục tiêu. Do đó chọn $\mathrm{p}=$ $30 \%$. Với $a=0,05$; tin câyy là $95 \%, z=1,96$; $d$ $=0,05$. Cỡ mẫu tính được 323 . Trong nghiên cứu này, chúng tôi có được 340 đối tượng.

Thu thập thông tin: Sử dụng kỹ thuật chọn mẫu thuận tiện, chọn đối tượng theo tiêu chuẩn chọn mấu và tiêu chí loại trừ. Tiến hành phỏng vấn theo bộ câu hỏi nghiền cứu.

Thời gian và địa điểm nghiên cứu: Khoa khám bệnh, Bệnh viện đa khoa Nhật Tân, An Giang, từ tháng 05/2021 đến tháng 7/2021

\subsection{Chỉ số và công cụ thu thập dữ liệu}

- Đặc điểm chung của đối tượng nghiên cứu: Gồm đặc điểm về nhân khẩu học (tuổi, giới, trình độ học vấn, nghề nghiệp) và một số đặc điểm, thói quen trong sinh hoạt liên quan đến bệnh (bệnh kèm theo, thời gian mắc bệnh, hút thuốc lá, uống rượu bia).

Chỉ số HbA1c (Hemoglobin A1c): HbA1c được đo bằng phương pháp HPLC trên hệ thống máy đo tự động Tosoh G8 của Nhật. HbÁ1c cho biết mức đường huyết trung bình trong 2 đến 3 tháng trước, qua đó đánh giá mức độ của bệnh hiện tại trên bệnh nhân ĐTĐ. Chúng tôi tìm mối liên quan của các yếu tố ảnh hưởng lên tình trạng bệnh ĐTĐ típ 2 thông qua nồng độ HbA1c của người bệnh.

- Hoạt động thể lực (HĐTL): Sử dụng bộ câu hỏi GPAQ (Global Physical Activity Questionaire) của WHO. HĐTL được đánh giá bằng năng lượng chuyển hóa tương đương (MET). MET là tỷ lệ của HĐTL cụ thể, thể hiện tỷ lệ trao đổi chất khi nghỉ ngơi. Một đơn vị MET bằng năng lượng ngồi yên lặng (1 kcal/kg/giờ). Theo WHO, trong 1 tuần, một người trưởng thành nên đạt ít nhất 600 MET-phút. Chúng tôi đưa ra 2 mức giá trị là: "Đủ" khi toàn bộ thời gian hoạt động $\geq 600$ MET-phút/tuần; và "Không đủ" khi toàn bộ thời gian hoạt động < 600 MET-phút/tuần.

- Thói quen và tuân thủ về chế độ ăn uống: Sử dụng bộ 20 câu hỏi PDAD (Patient Diet Adherence in diabetes) do Mariusz Jaworski và các cs phát triển theo hướng dẫn của Hiệp hội ĐTĐ $B a$ Lan và Tiêu chuẩn Chăm sóc $Y$ tế Bệnh ĐTÐ năm 2016 của ADA [3].Chúng tôi đưa ra 2 mức giá trị: "Tốt" khi tổng điểm >10, "Kém" $\leq 10$.

- Kiến thức người bệnh: Sứ dụng thang công cụ đo kiến thức về bệnh ĐTĐ do trung tâm nghiên cứu bệnh ĐTĐ Michigan phát triển. Công cụ này gồm một bộ 20 câu hỏi đúng/sai dùng cho dân cư có dân trí thấp như ở khu vực Nam Á. Trong đó có 16 câu kiến thức tổng hợp chung và 4 câu hỏi dành riêng cho đối tượng có sử dụng insulin [4]. Để thuận tiện so sánh chúng tôi sử dụng 16 câu hỏi chung cho cả 2 đối tượng và đưa ra 2 mức giá trị là: "Tốt" khi tổng điểm $>10$ và "Kém" khi tổng điểm $\leq 10$.

2.4. Xử lý thống kê: Xử lý bằng phần mềm SPSS 20.0. Các biến định tính được xử lý bằng cross-table. Khi so sánh các số trung bình, dùng ANOVA. Sau khi xử lý tất cả các biến có được trong nghiên cứu, tiếp tục phân tích bằng hồi quy tuyến tính đa biến. Số trung bình được biểu thị với \pm SD. Có ý nghĩa thống kê khi p<0,05.

2.5. Đạo đức trong nghiên cứu: Nghiên cứu được Hội đồng $Y$ đức của Bệnh viện đa khoa Nhật Tẩn thông qua. Người bệnh được giải thích về mục đích, ý nghĩa, các lợi ích và bất lợi có thể gặp phải và người bệnh tham gia hoàn toàn tự nguyện. 


\section{KẾT QUẢ NGHIÊN CỨU}

Bảng 1. Đặc điểm chung của đôi tượng ĐTĐ nghiên cứu

\begin{tabular}{|c|c|c|c|c|c|}
\hline \multicolumn{2}{|c|}{ Đắc điếm của đối tượng } & Số lượng $(n=340)$ & Tỷ lệ \% & HbA1c & $\mathbf{p}$ \\
\hline Giới tính & $\begin{array}{c}\text { Nũ̃ } \\
\text { Nam }\end{array}$ & $\begin{array}{l}237 \\
103\end{array}$ & $\begin{array}{l}69,7 \\
30,3\end{array}$ & $\begin{array}{l}8,89 \pm 1,87 \\
7,94 \pm 1,30\end{array}$ & $<0,001$ \\
\hline Nhóm tuổi & $\begin{array}{l}28-59 \\
60-86\end{array}$ & $\begin{array}{l}191 \\
149\end{array}$ & $\begin{array}{l}56,2 \\
43,8\end{array}$ & $\begin{array}{l}8,74 \pm 1,90 \\
8,42 \pm 1,58\end{array}$ & $>0,05$ \\
\hline $\begin{array}{l}\text { Nghề } \\
\text { nghiệp }\end{array}$ & $\begin{array}{l}\text { Nghề khác, hưu, nội trợ } \\
\text { Viên chức, công nhân }\end{array}$ & $\begin{array}{l}297 \\
43\end{array}$ & $\begin{array}{l}87,4 \\
12,6\end{array}$ & $\begin{array}{l}8,69 \pm 1,83 \\
7,96 \pm 1,34\end{array}$ & $<0,011$ \\
\hline $\begin{array}{l}\text { Trình độ } \\
\text { học vấn }\end{array}$ & $\begin{array}{c}\text { Tiêuu học } \\
\text { Phổ thông/cao đằng/đại học }\end{array}$ & $\begin{array}{l}212 \\
128\end{array}$ & $\begin{array}{l}62,4 \\
37,6\end{array}$ & $\begin{array}{l}8,85 \pm 1,81 \\
8,18 \pm 1,62\end{array}$ & $<0,010$ \\
\hline $\begin{array}{l}\text { Số năm } \\
\text { mắc bệnh }\end{array}$ & $\begin{array}{l}\geq 6 \text { năm (từ 6-34 năm) } \\
<6 \text { năm (từ 1-5 năm) }\end{array}$ & $\begin{array}{l}166 \\
174\end{array}$ & $\begin{array}{l}48,8 \\
51,2\end{array}$ & $\begin{array}{l}9,27 \pm 1,76 \\
7,96 \pm 1,53\end{array}$ & $<0,001$ \\
\hline
\end{tabular}

Nhận xét: Chỉ có nhóm tuối (28-59 và 60-86) không có ý nghĩa thống kê. Các yếu tố khác như giới nữ, nghề khác (về hưu, nội trợ, nghề khác), trình độ tiểu học và số năm mắc bệnh $\geq 6$ năm đều có nồng độ HbA1c cao nhóm còn lại, khác biệt có ý nghĩa thống kê với p<0,05.

Bảng 2. Thể trạng và các chỉ số sinh học của người bệnh ĐT円

\begin{tabular}{|c|c|c|c|c|c|}
\hline \multicolumn{2}{|c|}{ Các chỉ số của đối tượng } & $n=340$ & Tỷ lệ\% & HbA1c & $\mathbf{p}$ \\
\hline $\begin{array}{l}\text { BMI mục tiêu } \\
\mathrm{kg} / \mathrm{m}^{2}\end{array}$ & $\begin{array}{l}\geq 23 \mathrm{~kg} / \mathrm{m}^{2} \\
<23 \mathrm{~kg} / \mathrm{m}^{2}\end{array}$ & $\begin{array}{l}221 \\
109\end{array}$ & $\begin{array}{l}67,9 \\
32,1\end{array}$ & $\begin{array}{l}8,62 \pm 1,82 \\
8,56 \pm 1,67\end{array}$ & $>0,05$ \\
\hline Vòng eo & $\begin{array}{l}\geq \text { Ngưỡng (nam } \geq 94 ; \text { nữ } \geq 80 \mathrm{~cm} \text { ) } \\
<\text { Ngưỡng (nam <94; nữ <80 cm) }\end{array}$ & $\begin{array}{l}212 \\
128\end{array}$ & $\begin{array}{l}62,4 \\
37,6 \\
\end{array}$ & $\begin{array}{l}8,81 \pm 1,62 \\
8,24 \pm 1,75 \\
\end{array}$ & $<0,05$ \\
\hline $\begin{array}{l}\text { WHR, tỷ suất } \\
\text { eo-mông }\end{array}$ & $\begin{array}{l}\geq \text { Ngưỡng (nam } \geq 0,90 ; \text { nữ } \geq 0,85) \\
<\text { Ngươnng (nam <0,90; nữ <0,85) }\end{array}$ & $\begin{array}{c}285 \\
55\end{array}$ & $\begin{array}{l}83,8 \\
16,2 \\
\end{array}$ & $\begin{array}{l}8,74 \pm 1,79 \\
7,86 \pm 1,46 \\
\end{array}$ & $<0,001$ \\
\hline Huyết áp & $\begin{array}{l}\text { Tăng huyết áp } \\
\text { Không tăng huyết áp }\end{array}$ & $\begin{array}{l}144 \\
196 \\
\end{array}$ & $\begin{array}{l}42,4 \\
57,6\end{array}$ & $\begin{array}{l}8,84 \pm 1,96 \\
8,42 \pm 1,60 \\
\end{array}$ & $<0.05$ \\
\hline $\begin{array}{c}\text { MDRD ml/ } \\
\text { phút/1.73m² }\end{array}$ & $\begin{array}{l}\text { Từ trung bình đến nặng }<60 \\
\text { Bình thường đến giảm nhẹ } \geq 60\end{array}$ & $\begin{array}{c}38 \\
302\end{array}$ & $\begin{array}{l}11,2 \\
88,8\end{array}$ & $\begin{array}{l}8,60 \pm 1,80 \\
8,58 \pm 1,43\end{array}$ & $>0.05$ \\
\hline
\end{tabular}

Nhận xét: Vòng eo (nam $\geq 94$; nữ $\geq 80 \mathrm{~cm}$ ), WHR (nam $\geq 0,90 ;$ nữ $\geq 0,85$ ) và huyết áp thấp có nồng độ $\mathrm{HbA1c}$ cao hơn nhóm còn lại, có ý nghĩa với $p<0,05$. BMI và MDRD, không có ý nghĩa, $p>0,05$

Bảng 3. Một số thói quen sinh hoạt và kiến thức của người bệnh ĐTÐ

\begin{tabular}{|c|c|c|c|c|c|}
\hline \multicolumn{2}{|c|}{ Thói quen của đối tượng } & Số lượng ( $n=340)$ & Tỷ lệ \% & HbA1c & $\mathbf{p}$ \\
\hline Hoạt động thể lực & $\begin{array}{l}\text { Không đủ } \\
\text { Đủ }\end{array}$ & $\begin{array}{l}196 \\
144\end{array}$ & $\begin{array}{l}57,6 \\
42,4\end{array}$ & $\begin{array}{l}9,22 \pm 1,77 \\
7,74 \pm 1,38\end{array}$ & $<0,001$ \\
\hline Uống rượu bia & $\begin{array}{c}\text { Có } \\
\text { Không }\end{array}$ & $\begin{array}{c}51 \\
289\end{array}$ & $\begin{array}{l}15,0 \\
85,0\end{array}$ & $\begin{array}{l}8,09 \pm 1,34 \\
8,69 \pm 1,82\end{array}$ & $<0,05$ \\
\hline $\begin{array}{c}\text { Tuân thủ chế độ } \\
\text { ăn }\end{array}$ & $\begin{array}{l}\text { Kém } \\
\text { Tốt }\end{array}$ & $\begin{array}{l}155 \\
185\end{array}$ & $\begin{array}{l}45,6 \\
54,4\end{array}$ & $\begin{array}{l}8,81 \pm 1,73 \\
8,42 \pm 1,79\end{array}$ & $<0,05$ \\
\hline Hút thuốc lá & $\begin{array}{l}\text { Có hút } \\
\text { Không hút }\end{array}$ & $\begin{array}{c}30 \\
310\end{array}$ & $\begin{array}{c}8,8 \\
91,2\end{array}$ & $\begin{array}{l}8,12 \pm 1,47 \\
8,64 \pm 1,79\end{array}$ & $>0,05$ \\
\hline $\begin{array}{c}\text { Kiến thức về bệnh } \\
\text { ĐTĐ }\end{array}$ & $\begin{array}{l}\text { Kém } \\
\text { Tốt }\end{array}$ & $\begin{array}{l}196 \\
144\end{array}$ & $\begin{array}{l}57,6 \\
42,4\end{array}$ & $\begin{array}{l}8,65 \pm 1,83 \\
8,56 \pm 1,73\end{array}$ & $>0,05$ \\
\hline $\begin{array}{c}\text { Tuân thủ dùng } \\
\text { thuốc }\end{array}$ & $\begin{array}{l}\text { Không } \\
\text { Tuân thủ }\end{array}$ & $\begin{array}{l}225 \\
115\end{array}$ & $\begin{array}{l}66,2 \\
38,8 \\
\end{array}$ & $\begin{array}{l}9,14 \pm 1,81 \\
8,33 \pm 1,69\end{array}$ & $<0,001$ \\
\hline
\end{tabular}

Nhân xét: Hoạt động thể lực không đủ, tuân thủ chế độ ăn kém, không tuân thủ chế độ dùng thuốc, có nồng độ HbA1c cao hơn nhóm còn lại, khác biệt có ý nghĩa thống kê, $p<0,05$. Uống rượu bia có nồng độ $\mathrm{HbA1c}$ thấp hơn người không uống, $\mathrm{p}<0,05$, nhưng khi phân tích hồi qui đa biến thì không còn ý nghĩa thống kê. Hút thuốc lá và kiến thức về bệnh ĐTĐ không có ý nghĩa với $p>0,05$, Nhưng khi phân tích hồi qui đa biến thì kiến thức về bệnh ĐTĐ lại có ý nghĩa thống kêm, $p<0,05$.

Bảng 4. Lipid máu của đôi tượng

\begin{tabular}{|c|c|c|c|c|c|}
\hline \multicolumn{2}{|c|}{ Các chỉ số lipid máu của đối tượng } & n=340 & Tỷ lệ\% & HbA1c & P \\
\hline \multirow{2}{*}{ Cholesterol TP } & $\geq 5.2 \mathrm{mmol} / \mathrm{l}$ & 65 & 19,1 & $9,06 \pm 1,86$ & $<0,05$ \\
\hline HDI-Cholesterol & $<5.2 \mathrm{mmol} / /$ & 275 & 80,9 & $8,49 \pm 1,73$ & \\
\hline
\end{tabular}




\begin{tabular}{|c|c|c|c|c|c|}
\hline & $<1.03 \mathrm{mmol} / \mathrm{l}$ & 122 & 35,9 & $8.84 \pm 1.87$ & \\
\hline \multirow{2}{*}{ LDL-cholesterol } & $\geq 2.58 \mathrm{mmol} / \mathrm{l}$ & 166 & 48,8 & $8,89 \pm 1,88$ & $<0.001$ \\
& $<2.58 \mathrm{mmol} / \mathrm{l}$ & 174 & 51,2 & $8,32 \pm 1,62$ & \\
\hline \multirow{2}{*}{ Triglycerid } & $\geq 1.7 \mathrm{mmol} / \mathrm{l}$ & 213 & 62,6 & $8,671,77$ & $>0,05$ \\
\hline
\end{tabular}

Nhận xét: Chỉ có cholesterol toàn phần và LDL-cholesterol tăng cùng với HbA1c, $p<0,05$. Nhưng khi phẩn tích hồi qui tuyến tính đa biến thì tất cả các biến lipid đều không còn ý nghĩa thống kê.

Bảng 5. Các yếu tố ảnh hưởng tới HbA1c qua xử lý hồi quy đa biến.

\begin{tabular}{|c|c|c|c|c|c|}
\hline Các yếu tố & $\mathbf{B}$ & $\mathbf{B}_{\mathbf{s}}$ & $\mathbf{R}$ & $\mathbf{R}^{\mathbf{2}}$ & $\mathbf{p}$ \\
\hline Hoạt động thế lực & $-1,105$ & $-0,309$ & 0,412 & 0,170 & 0,000 \\
\hline Số năm mắc bệnh &, 993 & 0,281 & 0,371 & 0,137 & 0,000 \\
\hline Giới &,- 501 & $-0,130$ & 0,245 & 0,060 & 0,007 \\
\hline Tuân thủ dùng thuốc & $-0,381$ & $-0,102$ & 0,217 & 0,047 & $-0,030$ \\
\hline Tăng huyết áp & $-0,430$ & $-0,120$ & 0,117 & 0,014 & 0,010 \\
\hline Kiến thức người bệnh về ĐTĐ & 0,336 & 0,094 & 0,090 & 0,008 & 0,044 \\
\hline
\end{tabular}

Nhân xét: Khi phân tích bằng ANOVA, trong 20 biến thì có 14 biến có ý nghĩa thống kê, $\mathrm{p}$ $<0,05$. Do ĐTÐ (qua phân tích nồng độ $\mathrm{HbA1c}$ ) phụ thuộc rất nhiều biến độc lập khác, nên chúng tôi dùng hồi qui tuyến tính đa biến để xử lý. Khi phân tích chỉ còn 6 biến còn ý nghĩa thống kê. Riêng biến kiến thức người bệnh khi xử lý bằng ANOVA thì không có ý nghĩa thống kê, $\mathrm{p}>0,05$, nhưng qua hồi hồi qui thì lại có ý nghĩa, tuy yếu, với $p=0,044$. Qua phân tích hồi qui, hệ số tương quan $\mathrm{R}$ giữa $\mathrm{HbA1c}$ và hoạt động thể lực là cao nhất với $R=0,412$; sau đó giảm dần: số năm mắc bệnh , giới, tuân thủ dùng thuốc, tăng huyết áp và cuối cùng là kiến thức về ĐTĐ thấp nhất với $R=0,09$.

\section{BÀN LUÂ̂N}

Trong nghiên cứu của chúng tôi có 20 biến số được phân tích bằng ANOVA bao gồm các đặc điểm nhân khẩu học, thói quen sinh hoạt, thể trạng, kiến thức về bệnh và các chỉ số sinh học của người bệnh, trong đó có 7 biến không có ý nghĩa thống kê. Do nồng độ HbA1c phụ thuộc rất nhiều các biến độc lập, nên chúng tôi dùng hồi qui tuyến tính đa biển phân tích thì chỉ còn 6 biến khác biệt có ý nghĩa thống kê, $p<0,05$. Các biến này, chúng tôi sắp theo tương quan giảm dần giữa ĐTĐ típ 2 và các biến độc lập: Tương quan mạnh nhất là hoạt động thể lực với $\mathrm{R}=0,412$; số năm mắc bệnh với $\mathrm{R}=0,371$; giới tính với $R=0,245$; tuân thủ dùng thuốc với $R=0,217$; tăng huyết áp với $R=0,117$ và cuối cùng, cũng là biến tương quan kém nhất của HbA1c với $R=0,09$.

Mối tương quan của HbA1c và các biến độc lập từ mức độ mạnh đến yếu trong nghiên cứu của chúng tôi được bàn luận như dưới đây:

Người có hoạt động thể lực tốt nhất có nồng độ HbA1c thấp $7,74 \pm 1,38$ so với so với nhóm người ít hoạt động với HbA1c là $9,22 \pm 1,77$. Tăng cường hoạt động thể lực là một vấn đề chủ yếu và hiệu quả nhất của người bệnh ĐTĐ típ 2 mong muốn thuyên giảm bệnh. Beraki $\AA$ và cs [7] nghiên cứu ở Thụy Điển vào năm 2014 thây mức HbA1c trung bình ở nhóm ít hoạt động thể lực $8,8 \% \pm 1,5$ cao hơn so với nhóm hoạt động thể lực nhiêu $7,7 \% \pm 1,0, p<0,001$. Theo Beraki $\AA$ à̀ $c s$, mối liên quan này được tìm thây ở cả hai giới, và phân tích hồi quy cho thây mối quan hệ vẫn có ý nghĩa khi được điều chỉnh loại trừ các yếu tố gây nhiễu có thể xảy ra.

Một số tác giả cho rằng càng lớn tuổi, nguy cơ đề kháng insulin trong quá trình lão hóa cơ xương sẽ cung cấp lời giải thích toàn diện hơn cho việc gia tăng tỷ lệ mắc bệnh ĐTĐ loại 2 ở người cao tuổi và cũng sẽ cung cấp một quan điểm toàn diện hơn cho việc phòng ngừa và điều trị bệnh ĐTĐĐ típ 2 ở người cao tuổi. Trong nghiên cứu của chúng tôi, số năm mắc bệnh dưới 5 năm có nồng độ HbA1c 7,96 $\pm 1,53$ thấp hơn khi so với nhóm mắc $>6$ năm trở lên với $9,27 \pm 1,76$ khác biêt có ý nghĩa thống kê với $p<0,001$; khi phân tích hồi qui đa biến cũng có kết quả tương tự. Verma và cs [6] nghiên cứu trên 76 đối tượng, trong đó 30 người bình thường, không mắc bệnh ĐTÐ và 46 người còn lại là bệnh nhân ĐTÐ với thời gian khác nhau trong nhiêu năm được chẩn đoán mắc bệnh ĐTÐ. Kết quả thu được chỉ ra rằng mức $\mathrm{HbA} 1 \mathrm{c}$ gia tăng theo thời gian mắc bệnh ĐTÐ cũng như mức insulin cho thấy mối tương quan đáng kể sau khi điều chỉnh theo tuổi, giới tính và thời gian mắc bệnh ĐTÐ.Verma và cs cho rằng đây là do quá trình lão hóa hay bênh ĐTÐ khiến ngày càng tăng đề kháng insulin, vẫn còn nhiều gây tranh cãi.

Yếu tố về giới cũng ảnh hưởng nhiều đến nồng độ Hba1c. Nhiều tác giả cho rằng phụ nữ mắc bệnh ĐTÐ típ 2 kiểm soát đường huyết kém 
hơn nam giới. Nguyên nhân theo các tác giả này, có thể do khác biệt cân bằng nội môi glucose, đáp ứng điều trị và yếu tố tâm lý [5]. Trong nghiên cứu của chúng tôi, số bệnh nhân ĐTĐ là 340 , nữ chiếm $69,7 \%$ và nam chỉ $30,3 \%$. Nữ có nồng độ HbA1c 8,89 $\pm 1,87$ so với nam với 7,94 $\pm 1,30$, cao hơn $0,94 \pm 0,57$ so với nam, có ý nghĩa thống kê với $p<0,001$. Duarte và cs ở Nam Mỹ nghiên cứu trên 9418 bệnh nhân mắc bệnh ĐTÐ ở Brazil $(n=5692)$ và ở Venezuela $(n=$ 3726), bao gồm 6214 (66\%) phụ nữ và 3204 (34\%) nam giới. Mức HbA1c ở phụ nữ là cao hơn nam giới trung bình 0,13 (KTC 95\% 0,03 đến $0,24 ; p=0,015)$, sau khi hiệu chỉnh các biến độc lập như tuổi, tình trạng hôn nhân, giáo dục, chủng tộc, quốc gia, BMI, thời gian mắc bệnh, tuân thủ chế độ ăn uống, tuân thủ điều trị... [5].

Về tuân thủ dùng thuốc, nghiên cứu ở chúng tôi người không tuân thủ dùng thuốc chiếm tỷ lệ cao với $66,2 \%$ và cũng có nồng độ $\mathrm{HbA} 1 \mathrm{c}$ cao hơn $9,14 \pm 1,81$ so với người tuân thủ với tỷ lệ chỉ $38,8 \%$ và $\mathrm{HbA} 1 \mathrm{c}$ thấp hơn $8,33 \pm 1,69$, khác biệt có ý nghĩa thống kê với $p<0,05$. Muốn ổn định lượng đường, tuân thủ dùng thuốc cùng với các biện pháp khác mới dẫn tới thành công.

ĐTÐ típ 2 luôn đi kèm với tăng huyết áp là một diễn tiến thường gặp. Theo thời gian, bệnh ĐTÐ làm hỏng các mạch máu nhỏ trong cơ thể của người bệnh ĐTÐ, khiến thành mạch cứng lại. Điều này làm tăng áp lực, từ đó dẫn đến huyết áp cao. Nghiên cứu của chúng tôi tỷ lệ tăng huyết áp ở nhóm người ĐTĐ là $42,4 \%$ và HbA1c trung bình là $8,84 \pm 1,96$; trong nhóm người không tăng huyết áp chiếm $57,6 \%$, có nồng độ HbA1c thấp hơn 8,42 $\pm 1,60, \mathrm{p}<0,05$.

Sư hiểu biết của người bênh về ĐTĐ luôn là yếu tố quan trọng góp phần kiểm soát có hiệu quả bệnh ĐTÐ típ 2, nghiên cứu của chúng tôi nồng độ $\mathrm{HbA1c}$ của nhóm hiểu biết kém và hiểu biết tốt lần lượt là $8,65 \pm 1,83$ so với $8,56 \pm$ 1,73 . Sau khi phân tích hồi qui tuyến tính thì sự hiểu biết về ĐTĐ của người bệnh cũng đã góp phần vào hiệu quả điều trị với $p<0,05$. Công trình của Christie và cs [8] cũng chứng minh sự hiểu biết của người bệnh về ĐTĐ góp phần phá võ̃ các rào cản và là cớ hội để cải thiện nồng độ HbA1c.

\section{KẾT LUÂ̂N}

Các yếu tố liên quan đễn giảm nồng độ HbA1c trong nghiên cứu này bao gồm có hoạt động thể lực tốt, ĐTĐ típ 2 dưới $<6$ năm, giới tính nam, tuân thủ dùng thuốc tốt, kiểm soát huyết áp tốt, có kiến thức tốt về bệnh. Các yếu tố ảnh hưởng trong nghiên cứu của chúng tôi, có những yếu tố không thể điêu chỉnh được như giới tính, số năm mắc bệnh. Nhưng có các yếu tố ảnh hưởng khác có thể điều chỉnh ở người bệnh ĐTÐ típ 2 như tăng cường hoạt động thể lực, tăng cường giáo dục kiến thức về phòng và điều trị bệnh ĐTĐ típ 2, kiểm soát huyết áp tốt và cần tuân thủ dùng thuốc. Nếu thực hiện các khuyến cáo trên đây, việc phòng chống "dịch ĐTĐ típ 2" mới có hiệu quả, góp phần giảm bớt gánh nặng về bệnh tật cho cộng đồng dân cứ.

\section{TÀI LIẸU THAM KHẢO}

1. International Diabetes Federation. IDF diabetes atlas in International Diabetes Federation, 1-144, Brussels, Belgium, 9th edition; 2019: http://wwwdiabetesatlas.org.

2. Bô Y tế. Hướng dấn chẩn đoán và điêu tri đái tháo đường típ 2. Quyết định số 5481QĐ-BYT, ngày 30 tháng 12 năm 2020.

3. Mariusz Jaworski, Mariusz Panczyk Małgorzata Cedro, Alícja Kucharska. Adherence to dietary recommendations in diabetes mellitus: disease acceptance as a potential mediator. Patient Prefer Adherence. 2018 Jan 24;12:163-174

4. Michigan Diabetes Research Center. Tools for Health Professionals: Diabetes Knowledge Test - (DKT). http://diabetesresearch.med.umich.edu/Tools_Sur veyInstruments.php

5. Duarte FG, Moreira SS, Almeida MCC, Teles CAS, Andrade CS, Reingold AL, Moreira Jr ED. Sex differences and correlates of poor glycaemic control in type 2 diabetes: a cross-sectional study in Brazil and Venezuela. BMJ Open 2019;9:e023401. doi:10.1136/bmjopen-2018023401.

6. Verma M,Paneri S, Badi P, Raman PG. Effect of increasing duration of diabetes mellitus type 2 on glycated hemoglobin and insulin sensitivity. Indian J Clin Biochem. 2006 Mar; 21(1): 142-146.

7. Beraki Å, Magnuson A, Särnblad S, Åman J, Samuelsson U. Increase in physical activity is associated with lower $\mathrm{HbA} 1 \mathrm{c}$ levels in children and adolescents with type 1 diabetes: results from a cross-sectional study based on the Swedish pediatric diabetes quality registry (SWEDIABKIDS). Diabetes Res Clin Pract. 2014 Jul;105(1):119-25.

8. Christie $D$, Thompson $R$, Sawtell $M$, Allen E, Cairns J, Smith F, Jamieson E, Hargreaves K, Ingold A et al. Structured, intensive education maximising engagement, motivation and long-term change for children and young people with diabetes: a cluster randomised controlled trial with integral process and economic evaluation - the CASCADE study. Health Technol Assess. 2014 Mar;18(20):1-202.

9. Roseanne 0 Yeung, Yuying Zhang (2014), "Metabolic profiles and treatment gaps in youngonset type 2 diabetes in Asia (the JADE programme): a cross-sectionalstudy of a prospective cohort", Lancet Diabetes Endocrinol, 2, pp:935-43 